\title{
Can Periodical Examinations of Employees Be Useful in Detection of Glycaemia Impairment and Improving Patients' Adherence to Medical Recommendations?
}

\author{
Andrzej Marcinkiewicz ${ }^{1, *(1)}$, Wojciech Hanke ${ }^{2}$, Paweł Kałużny ${ }^{2}$, \\ Agnieszka Lipińska-Ojrzanowska ${ }^{1}$, Marta Wiszniewska ${ }^{1}$ and Jolanta Walusiak-Skorupa ${ }^{1}$ \\ 1 Department of Occupational Diseases and Environmental Health, Nofer Institute of Occupational Medicine, \\ 91-348 Łódź, Poland; agnieszka.lipinska-ojrzanowska@imp.lodz.pl (A.L.-O.); \\ marta.wiszniewska@imp.lodz.pl (M.W.); jolanta.walusiak-skorupa@imp.lodz.pl (J.W.-S.) \\ 2 Department of Environmental Epidemiology, Nofer Institute of Occupational Medicine, 91-348 Łódź, \\ Poland; wojciech.hanke@imp.lodz.pl (W.H.); pawel.kaluzny@imp.lodz.pl (P.K.) \\ * Correspondence: and.mar@interia.pl; Tel.: +48-600-438-080
}

Received: 3 March 2018; Accepted: 27 March 2018; Published: 30 March 2018

\begin{abstract}
Worldwide epidemiological data indicates insufficient diagnosis of diabetes as an increasing public health problem. In the search for solutions to this disadvantageous situation, occupational medicine health services seem to open up a unique opportunity to recognize some abnormalities in the early stages, especially among the asymptomatic working-age population. 316 workers underwent obligatory prophylactic examinations. In patients with twice assayed FGL $\geq 126 \mathrm{mg} / \mathrm{dL}$ $(7.0 \mathrm{mmol} / \mathrm{L})$ an additional intervention was implemented, including further diagnostic processes and therapy in General Practice (GP), followed by examination by an occupational health specialist within 3 months. The diagnosis of previously unknown diabetes was established among $2.5 \%$ of examined workers. All patients referred to the GP due to detected glycaemia impairment visited their doctor and finished the diagnostic process, took up therapy constrained by the occupational health physician to show the effects of intervention within 3 months. Prophylactic medical check-ups allow improved compliance and medical surveillance over glycaemia impairment in patients with prediabetes states, unknown diabetes or uncontrolled clinical course of diabetes. Considering fasting glucose level during mandatory prophylactic examination helps effective prevention of diabetes and its complications and thus provides public health system benefits.
\end{abstract}

Keywords: occupational health; diabetes; glycaemia impairment; impaired fasting glucose; adherence; compliance

\section{Introduction}

Worldwide epidemiological data indicates insufficient diagnosis of diabetes mellitus (DM) as an increasing problem, as even in developed countries the DM diagnostic rate stands at about $64.2 \%$ [1]. Due to the availability of a low-cost screening tool like the measurement of fasting glucose blood level, under-recognizing DM may be interlinked with inconsistencies of the healthcare system, which should provide effective and comprehensive solutions to this issue (in the legal, institutional, organizational, financial and educational aspects). Searching for solutions in this disadvantageous situation, occupational medicine health services seem to offer a unique opportunity to recognize abnormalities in their early stages, especially among the asymptomatic working-age population. About 4 million mandatory employee examinations are carried out yearly in Poland among a population of over 12.5 million in an economically productive age [2]. However, the level of glycaemia in the blood is routinely estimated only in a determined group of workers whose jobs are related to public 
safety (e.g., drivers) or among workers voluntarily participating in supplementary health preventive programs financed by employers. Mandatory periodical prophylactic examinations may offer a chance for effective prevention of diabetes in the scope of the development of this disease and its complications. Workers' health checkups are reasonable due to possible detection of prediabetes states (impaired fasting glucose or impaired glucose tolerance), which may be reversible (contrary to diabetes) if effective preventive methods are implemented. Certainly, it is a matter not only of performing a laboratory test, but also of educating a patient in different aspects of a healthy lifestyle and of his adherence to these precautions. Nowadays, a number of terms, e.g., 'compliance', 'adherence', 'persistence', and 'concordance', are used to define different aspects of the act of seeking medical attention, acquiring prescriptions and taking medicines appropriately [3]. However, in this aspect adherence, which describes the extent to which a person's behaviour-taking medication, following a diet, and/or executing lifestyle changes, corresponds with agreed recommendations from a health care provider [3] and seems the most appropriate.

The aim of this study was to evaluate if mandatory periodical prophylactic examinations carried out in Poland may be used to improve the detection of glycaemia impairment among asymptomatic and unaware workers and of their adherence to medical recommendations.

\section{Materials and Methods}

The study group comprised 316 workers referred by various employers to mandatory medical examinations in the period of February-July 2015. Medical check-ups were carried out in the occupational medicine outpatient clinic located in a city in central Poland with a population of 60,000 . The criterion for exclusion from the study was previously diagnosed diabetes.

Among 305 patients without a previous diagnosis of diabetes, the fasting glucose level (FGL) in venous blood was assayed by a laboratory method. All of the patients with FGL 100-125 mg/dL (5.6-6.9 $\mathrm{mmol} / \mathrm{L})$ were educated about the necessity of reducing the modifiable risk factors for DM and further glycaemia control in General Practice (GP). Among patients with FGL $>125 \mathrm{mg} / \mathrm{dL}$ ( $>6.9 \mathrm{mmol} / \mathrm{L})$, another assay was carried out. In case of FGL $\geq 126 \mathrm{mg} / \mathrm{dL}(7.0 \mathrm{mmol} / \mathrm{L})$ measured in both the 1st and the 2nd assay, that is a criterion qualifying the recognition of diabetes [4], the study intervention procedure was implemented, including referral to a GP for confirmation of the diagnosis and taking up therapy, and the following term of re-examination by an occupational health specialist was established within 3 months. In this period of time, workers with suspected DM had to visit their GPs for further diagnostics. They were then obligated to bring medical information from their GP (about actions taken and their effects) during the next mandatory prophylactic examination carried out in a reduced term-3 months (Figure 1).

Moreover, all of the workers completed a questionnaire of the Findrisc form (which determines of total risk score for developing type 2 diabetes within the next 10 years) [5] and were interviewed about previous glycaemia measurements and further steps in case of detected glycaemia impairment in the past.

As for the characteristics of the study participants the following potential binary factors for glycaemia impairment (based on data from the Findrisc form) were determined: gender, age $>45$ years, body mass index (BMI) $\geq 25 \mathrm{~kg} / \mathrm{m}^{2}$, abdominal obesity: waist circumference in men $>94 \mathrm{~cm}$ and in women $>80 \mathrm{~cm}$, low-intensity of usual physical activity (below at least $30 \mathrm{~min}$ a day), inappropriate nutrition (unbalanced and poor in vegetables and fruit), family history of DM, detection of glycaemia impairment in the past or lack of prior glycaemia assays.

Statistical analysis applied a crude risk index represented by an odds ratio (OR) of DM incidence in the group with present risk factor of diabetes in relation to the group without this risk factor, together with $95 \%$ confidence interval $(95 \% \mathrm{CI})$. Statistical calculations were conducted using the R software [6]. 
Mandatory prophylactic examination of 316 workers by an occupational health physician

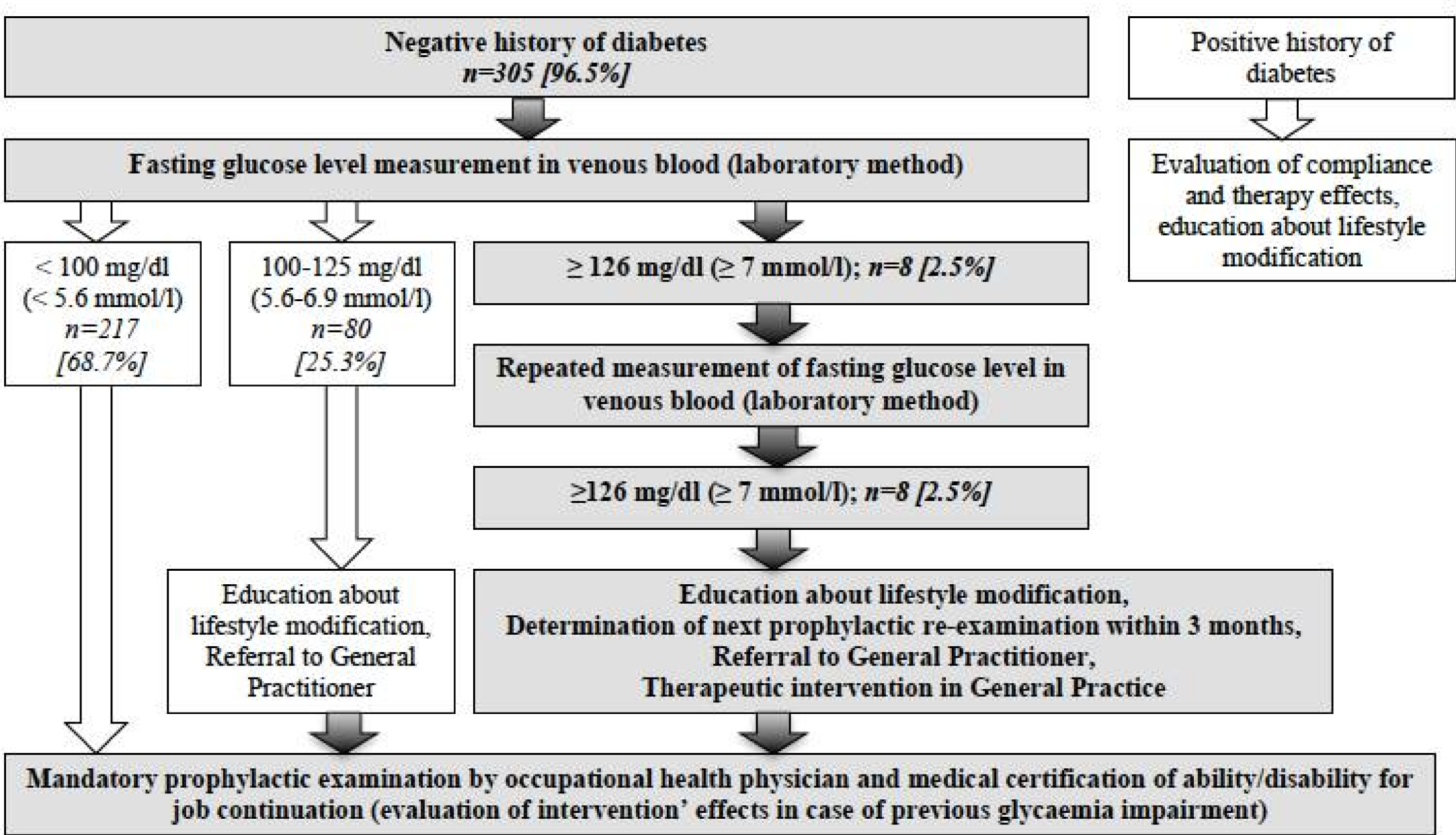

Figure 1. Chart of the study design and intervention implemented among workers with a recognized glycaemia impairment. 
The study protocol was approved by the local Bioethical Committee at the Nofer Institute of Occupational Medicine in Lodz (decision number 04/2015, 18 February 2015). Participation in the study required an informed written consent.

\section{Results}

The study group comprised 316 workers (198 men and 118 women) aged 19-68. The mean age averaged $41.9 \pm 11.66$ years (mean $\pm \mathrm{SD}$ ) and was higher among male employees ( $42.6 \pm 11.67$ years) than female (40.9 \pm 11.61 years). Six men ( $3 \%)$ and five women $(4.2 \%)$ reported suffering from diabetes. In 305 workers without a previous diagnosis of DM, FGL in blood was assayed. In 74 men (37.4\%) and 14 women (11.9\%) FGL was elevated, among them in 67 males and 12 females FGL ranged $100-125 \mathrm{mg} / \mathrm{dL}$ (5.6-6.9 mmol/L) (Figure 2).
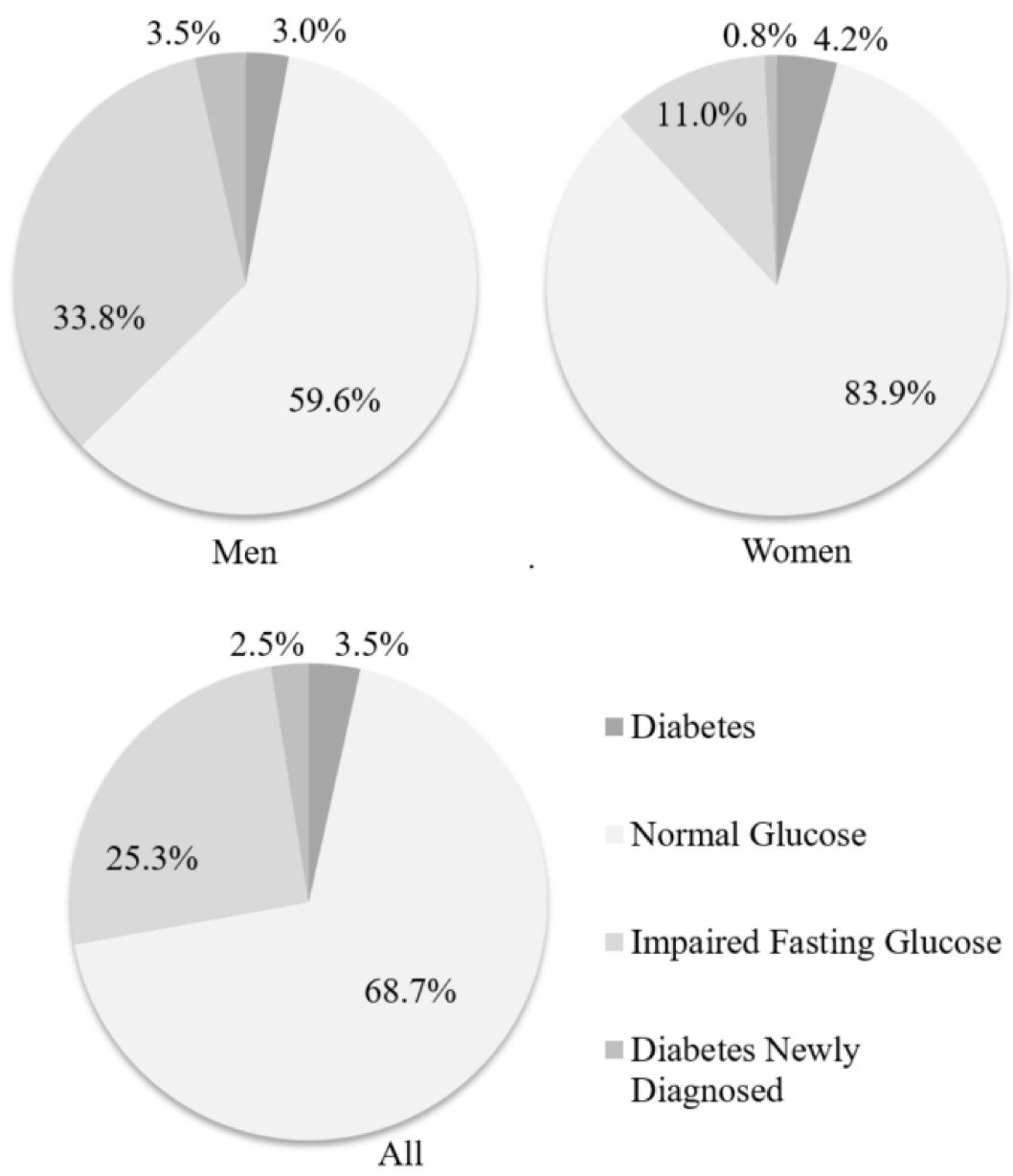

Figure 2. Glycaemia impairment in the study group of workers $(n=316)$.

In $2.5 \%$ of workers who underwent prophylactic examinations previously unknown diabetes was detected (Figure 2): in eight workers (seven men and one woman) in the 1st assay, and then in the 2nd assay as well, FGL exceeded $126 \mathrm{mg} / \mathrm{dL}(7.0 \mathrm{mmol} / \mathrm{L})$. Due to the established criterion of study intervention, those patients were referred to a GP where finally diabetes was diagnosed in all 8 people and treatment was implemented. This means that $100 \%$ of patients have followed medical recommendations.

The most important risk factors of DM in male workers were: overweight, abdominal obesity, low daily vegetable and fruit intake and low usual physical activity. The major pitfalls in female workers were: abdominal obesity, insufficient physical activity and family history of DM (Table 1). 
Table 1. Characteristics of the study participants without previous recognition of diabetes $(n=305)$.

\begin{tabular}{|c|c|c|c|}
\hline Risk Factor & Males $n=192(\%)$ & Females $n=113(\%)$ & Both $n=305(\%)$ \\
\hline $\mathrm{BMI}>25 \mathrm{~kg} / \mathrm{m}^{2}$ & $137(71)$ & $38(34)$ & $175(57)$ \\
\hline Low daily physical activity * & $81(42)$ & $57(50)$ & $138(45)$ \\
\hline Improper diet ** & $82(43)$ & $30(26)$ & $112(37)$ \\
\hline History of arterial hypertension & $46(24)$ & $14(12)$ & $60(20)$ \\
\hline Lack of glycaemia impairment control *** & $18(9)$ & $4(3)$ & $22(7)$ \\
\hline Lack of previous glycaemia testing & $64(33)$ & $33(29)$ & $97(32)$ \\
\hline
\end{tabular}

BMI—Body Mass Index; F-Females; M-Males; $n$-number of; WC—waist circumference; * Low daily physical activity-according to Findrisc form [5] lack of at least $30 \mathrm{~min}$ of daily physical activity; ** Improper diet-according to Findrisc form [5] diet poor in vegetables and fruit; ${ }^{* * *}$ Lack of following control tests despite detection of glycaemia impairment.

The associations of these factors with the risk of glycaemia impairment is summarized in Table 2. It revealed that most factors were related to hyperglycemia in males and females in similar way. Among lifestyle-related factors in men, the odds for glycaemia impairment were 5.37 times increased in abdominal-obese subjects (95\% CI: 2.67-10.82). Remarkably, the odds of glycaemia impairment were not significantly increased (OR $0.99 ; 95 \%$ CI: $0.54-1.84$ ) in the group of men with family history of diabetes, although prevalence of this condition reached $34 \%$ (Table 1). The risk of impaired glycaemia was also increased among male workers with overweight (OR 3.41; 95\% CI: 1.62-7.15) with low daily physical activity (OR 2.26; 95\% CI: 1.25-4.09). Previous episodes of elevated but neglected FGL were strong predictor for impaired glycaemia. Among women, the prevalence of glycaemia impairment was smaller $(11 \%)$ than among men (33.8\%) and therefore the estimates of risk were less reliable.

Table 2. Risk factors for development of the impaired carbohydrate metabolism evaluated in the study group without the prior diagnosis of diabetes $(n=305)$.

\begin{tabular}{|c|c|c|c|c|c|c|}
\hline \multirow[b]{2}{*}{ Risk Factor } & \multicolumn{3}{|c|}{ Males $(n=192)$} & \multicolumn{3}{|c|}{ Females $(n=113)$} \\
\hline & $\begin{array}{l}\text { FGL at Reference } \\
\text { Range <100 } \\
\text { mg/dL } n=118(\%)\end{array}$ & $\begin{array}{c}\mathrm{FGL} \geq 100 \\
\mathrm{mg} / \mathrm{dL} \\
n=74(\%)\end{array}$ & OR $(95 \% \mathrm{CI})$ & $\begin{array}{c}\text { FGL at Reference } \\
\text { Range }<100 \\
\text { mg/dL } n=99(\%)\end{array}$ & $\begin{array}{c}\text { FGL } \geq 100 \\
\mathrm{mg} / \mathrm{d} L \\
n=14(\%)\end{array}$ & OR $(95 \% \mathrm{CI})$ \\
\hline $\mathrm{BMI} \geq 25 \mathrm{~kg} / \mathrm{m}^{2}$ & $74(62.7)$ & $63(85.1)$ & $3.41(1.62-7.15)$ & $28(28.3)$ & $10(71.4)$ & $6.34(1.84-21.89)$ \\
\hline Abdominal obesity * & 55 (46.6) & $61(82.4)$ & $5.37(2.67-10.82)$ & $46(46.5)$ & $12(85.2)$ & $6.91(1.47-32.51)$ \\
\hline Low daily physical activity ** & $41(34.47)$ & $40(54.1)$ & $2.26(1.25-4.09)$ & $46(46.5)$ & 11 (78.6) & $4.22(1.11-16.07)$ \\
\hline Improper diet $* * *$ & $52(44.1)$ & $30(40.5)$ & $0.87(0.48-1.56)$ & $27(27.3)$ & $3(21.4)$ & $0.73(0.19-2.81)$ \\
\hline $\begin{array}{l}\text { Positive history of } \\
\text { glycaemia impairment }\end{array}$ & $8(7)$ & $23(31)$ & $6.20(2.59-14.81)$ & $5(5)$ & $5(36)$ & $\begin{array}{c}10.44 \\
(2.53-43.02)\end{array}$ \\
\hline $\begin{array}{l}\text { Lack of glycaemia } \\
\text { impairment control }\end{array}$ & $4(3)$ & $14(19)$ & $6.65(2.09-21.09)$ & $2(2)$ & $2(14)$ & $8.08(1.04-62.76)$ \\
\hline $\begin{array}{l}\text { Lack of previous } \\
\text { glycaemia testing }\end{array}$ & $45(38)$ & $19(26)$ & $0.56(0.29-1.06)$ & $31(31)$ & $2(14)$ & $0.36(0.07-1.73)$ \\
\hline
\end{tabular}

The odds for glycaemia impairment for females was also increased by abdominal obesity (OR 6.91; CI: 1.47-32.51), overweight (OR 6.34; CI: 1.84-21.89) but unrelated to family history of diabetes (OR 1.74; CI: 0.56-5.38). No significant association between glycaemia impairment and lack of FGL assay in the past, was revealed (OR 0.56 (CI: 0.29-1.06) in men, and 0.36 (CI: 0.07-1.73) in women). Among men glycaemia impairment was also significantly positively associated with age over 45 years and with co-existing arterial hypertension (Table 2).

On the basis of the Findrisc form, $72.5 \%$ of the study participants had a low or slightly elevated risk of diabetes type 2 occurrence in the following 10 years. In this group, 37 workers (17\%) had IFG and one case of FGL $\geq 126 \mathrm{mg} / \mathrm{dL}(7.0 \mathrm{mmol} / \mathrm{L})$ was detected. Among other employees with at least a 
moderate risk of diabetes type 2 occurrence in the following 10 years, seven cases of FGL $\geq 126 \mathrm{mg} / \mathrm{dL}$ ( $7.0 \mathrm{mmol} / \mathrm{L}$ ) and as a consequence DM were observed, and 43 subjects had IFG (Table 3 ).

Table 3. The risk of developing diabetes type 2 within the next 10 years in patients with detected glycaemia impairment and without a prior diagnosis of diabetes $(n=305)$. According to Findrisc form [5].

\begin{tabular}{|c|c|c|c|c|}
\hline \multirow[b]{2}{*}{$\begin{array}{l}10 \text { Years Risk of DM } \\
\text { Type } 2 \text { Development }\end{array}$} & \multirow[b]{2}{*}{ All $n=305(\%)$} & \multicolumn{3}{|c|}{ Fasting Glucose Level in Venous Blood } \\
\hline & & $\begin{array}{c}70-99 \mathrm{mg} / \mathrm{dL} \\
(3.9-5.5 \mathrm{mmol} / \mathrm{L}) \\
n=217(\%)\end{array}$ & $\begin{array}{c}100-125 \mathrm{mg} / \mathrm{dL} \\
(5.6-6.9 \mathrm{mmol} / \mathrm{L}) \\
n=80(\%)\end{array}$ & $\begin{array}{c}\geq 126 \mathrm{mg} / \mathrm{dL} \\
(7.0 \mathrm{mmol} / \mathrm{L}) \\
n=8(\%)\end{array}$ \\
\hline Low $(<1 \%)$ & $141(46.2)$ & $123(87.2)$ & $18(12.8)$ & 0 \\
\hline Slightly elevated (4\%) & $80(26.2)$ & $60(75)$ & $19(23.8)$ & $1(1.3)$ \\
\hline Moderate $(16.6 \%)$ & 34 (11.1) & $16(47.1)$ & $15(44.1)$ & $3(8.8)$ \\
\hline High (33\%) & $44(14.4)$ & $16(36.4)$ & $26(59.1)$ & $2(4.5)$ \\
\hline Very high (50\%) & $6(2.0)$ & $2(33.3)$ & $2(33.3)$ & $2(33.3)$ \\
\hline
\end{tabular}

DM-diabetes mellitus; Total risk score for developing type 2 diabetes within next 10 years according to Findrisc form [5]: $<7$ pc-low: estimated 1 in 100 persons will develop DM type 2. 7-11 pc-slightly elevated: estimated 1 in 25 persons will develop DM type 2. 12-14 pc-moderate: estimated 1 in 6 persons will develop DM type 2 . 15-20 pc-high: estimated 1 in 3 persons will develop DM type $2>20$ pc-very high: estimated 1 in 2 persons will develop DM type 2.

\section{Discussion}

In this study, during mandatory prophylactic examinations, $3.5 \%$ of workers declared previous recognition of diabetes, that is less than the estimated prevalence for the Polish population aged 20-79, which is about $7.9 \%$ [1]. It is possible that a few patients intentionally dissimulated the disease due to fear of losing the ability to continue their earning job.

Glycaemia impairment was detected in $33.8 \%$ of examined men, that is more than the estimated prevalence for prediabetes states, including impaired fasting glucose (IFG) or impaired glucose tolerance (IGT) among Polish males in general (5.8\% \pm 1.02$)$. An elevated level of fasting glucose was observed in $11 \%$ of women, that is similar to the estimated prevalence of prediabetes states among Polish females as a whole $(7.25 \% \pm 1.05)$ [7].

The cause of high prevalence of glycaemia impairment among men may be found in the co-existing typical risk factors for diabetes development, especially more frequent, in comparison with the Polish general population, occurrence of overweight (BMI $>25 \mathrm{~kg} / \mathrm{m}^{2}: 71 \%$ vs. $61.6 \%$ ) [8]. In the study group of females, the prevalence of overweight was lower in comparison with Polish general population (approximately $34 \%$ vs. $50.3 \%$ ) [8].

Fasting glucose level in venous blood assay carried out in all workers examined during mandatory prophylactic examinations resulted in a diagnosis of $8(2.5 \%)$ previously unknown cases of DM, which corresponds with the prevalence of unknown diabetes estimated for the Polish general population [1].

It is worth emphasizing that the fasting glucose blood level was measured in venous blood in all of the study participants, and only a positive history of DM constituted an excluding criterion of implementing the intervention. Obligatory glycaemia testing in all employees referred to occupational health physician examinations gave the opportunity to reveal an undiagnosed diabetes with an equal prevalence estimated for the general population. Similarly, Krogsbøll et al., indicated a positive correlation between common health control (not directed on specific abnormalities) and de novo established recognition of health disturbances [9]. However, these researchers also paid attention to a previous lack of data about any impact of these control medical check-ups a decrease in morbidity and mortality. Furthermore, a lot of studies have been published, critically referring to the purpose and effectiveness of general preventive action as part of mandatory examinations of employees [10,11]. On the contrary, the results of our study confirmed the real opportunity for detection of undiagnosed diabetes during prophylactic mandatory periodical examinations, as well as to improve adherence that may reduce both morbidity and mortality. The most important role seems to be played by an appointment of a day of the following mandatory medical check-up in short period of time just after 
the detection of glycaemia impairment. The pressure put on workers caused by establishing the following examination by the occupational health physician within 3 months resulted in a higher adherence to medical advice (100\% of employees took up diagnostics/therapy of DM in GP). Previous literature has suggested that only $36-93 \%$ of patients comply with medical advices related to therapy and $10-80 \%$ comply with medical advices related to unhealthy lifestyle modification [12].

Among workers, who denied DM recognition in the past, $33 \%$ of men and $29 \%$ of women admitted to having never had glycaemia testing (comparing with the study carried out by Kobuszewska et al.: $37.7 \%$ of males and $17.9 \%$ females in the age below 65 years old [13]). The majority of persons with elevated FGL in the past, consulted further diagnostic steps with their GP, however $7 \%$ disregarded that result.

Fasting glucose level testing seems to be the most justified in employees subjected to prophylactic examinations who have an increased risk of metabolic disorders. The Findrisc form is a commonly available screening tool for the prediction of DM type 2 development in the near future within 10 years [5,14-16]. The results of our study, performed by using the Findrisc form, revealed the distribution of the risk of diabetes in examined workers to be similar to the research conducted by Vandermissen et al., among 275 workers with the average age of 45 years (in our study more patients with a higher risk of DM participated: approximately $14.4 \%$ vs. $4.4 \%$ ) [17]. What is more, contrary to this research [17], not all cases of hyperglycaemia $\geq 126 \mathrm{mg} / \mathrm{dL}(7.0 \mathrm{mmol} / \mathrm{L})$ were associated with a moderate or higher risk of DM occurrence ( $>12$ pc on the Findrisc scale). Also, Bergmann et al., indicated towards a lower effectiveness for this tool in the detection of asymptomatic diabetes type 2 [18]. Witte et al., suggested that non-invasive methods of risk assessment requiring further improvement, testing and validation before their implementation as a 1st step in screening diagnostic procedures for diabetes [19].

The study has few shortcomings. The one of them is relatively low number of examined subjects. The only bias we were able to identify is possibly linked to the selection of the population which was done based on schedule provided by employers. However, we do not think it is substantial. We do not know any sources which might possible influence the selection of examined group and to prevent it to be is a good representation of the entire population of workers undergoing preventive examinations in central Poland area.

The strength of the study is proving the potential of employees' health check-ups for prophylactic purposes. Further research directions should comprise comprehensive examinations in bigger groups as well as follow up to evaluate the results of the intervention.

\section{Conclusions}

It may be worth including fasting glucose blood testing in the scope of prophylactic mandatory examinations of workers due to further health benefits and effective prevention of diabetes that may be also cost-effective for general health preventive services [20]. The obligatory nature of these medical check-ups provides an opportunity for early recognition of undiagnosed diabetes and to improve the patient's adherence to medical recommendations. A diagnosis of prediabetes states should result in further diagnostic steps, health education and the implementation of preventive activities in the workplace, which are known to be effective [21,22]. Periodical prophylactic examinations of workers, therefore, can successfully fit in the modern model of active diagnosis of asymptomatic population diseases and thus give public health system benefits.

Acknowledgments: The study was conducted as part of the Nofer Institute of Occupational Medicine project IMP 12.24 entitled "Elaboration of standards of secondary prevention in hypertension and diabetes during prophylactic examinations of workers" financed with the resources granted by the Ministry of Science and Higher Education. Project manager: Andrzej Marcinkiewicz.

Author Contributions: Andrzej Marcinkiewicz, as the first author, conceived and designed the research, performed the research, analyzed the qualitative data, and drafted the whole manuscript; Wojciech Hanke provided suggestions on preparing the article, and analyzed the qualitative data; Paweł Kałużny was responsible 
for quantitative data analysis, Agnieszka Lipińska-Ojrzanowska prepared of references, Marta Wiszniewska analyzed the qualitative data, Jolanta Walusiak-Skorupa substantively revised the whole manuscript.

Conflicts of Interest: The authors declare no conflict of interest.

\section{References}

1. International Diabetes Federation. IDF Diabetes Atlas-Seventh Edition. 2015. Available online: http: / / www.diabetesatlas.org (accessed on 15 February 2017).

2. Marcinkiewicz, A.; Wojda, M.; Walusiak-Skorupa, J.; Hanke, W.; Rydzyński, K. The analysis of tasks realized by occupational health services in Poland from 1997 to 2014. Do we exploit the full potential of prophylactic examinations of workers? Med. Pr. 2017, 68, 105-119. [CrossRef] [PubMed]

3. Vrijens, B.; De Geest, S.; Hughes, D.A.; Kardas, P.; Demonceau, J.; Ruppar, T.; Dobbels, F.; Fargher, E.; Morrison, V.; Lewek, P.; et al. A new taxonomy for describing and defining adherence to medications. Br. J. Clin. Pharmacol. 2012, 73, 691-705. [CrossRef] [PubMed]

4. Polish Diabetes Association. Guidelines on the management of diabetic patients. A position of Polish Diabetes Association. Clin. Diabetol. 2015, 4 (Suppl. A), A1-A73. (In Polish)

5. Lindstrom, J.; Tuomilehto, J. The diabetes risk score: A practical tool to predict type 2 diabetes risk. Diabetes Care 2003, 26, 725-731. [CrossRef] [PubMed]

6. R Core Team. R: A Language and Environment for Statistical Computing, version 3.3; R Foundation for Statistical Computing: Vienna, Austria, 2017.

7. Wittek, A.; Sokalski, B.; Grzeszczak, W.; Strojek, K. Prevalence of Diabetes and Cardiovascular Risk Factors of Industrial Area in Southern Poland. Exp. Clin. Endocrinol. Diabetes 2009, 117, 350-353. [CrossRef] [PubMed]

8. Biela, U.; Pająk, A.; Kaczmarczyk-Chałas, K.; Głuszek, J.; Tendera, M.; Waśkiewicz, A.; Kurjata, P.; Wyrzykowski, B. Incidence of overweight and obesity in women and men between the ages of 20-74. Results of the WOBASZ program. Kardiol. Pol. 2005, 63 (Suppl. 4), 1-4. (In Polish)

9. Krogsbøll, L.T.; Jørgensen, K.J.; Larsen, C.G.; Gøtzsche, P.C. General health checks in adults for reducing morbidity and mortality from disease: Cochrane systematic review and meta-analysis. BMJ 2012, 345, e7191. [CrossRef] [PubMed]

10. Rodrigez-Jareno, M.C.; Molinero, E.; de Montserrat, J.; Valles, A.; Aymerich, M. How much do workers' health examinations add to health and safety at the workplace? Occupational preventive usefulness of routine health examinations. Gac. Sanit. 2015, 29, 266-273. [CrossRef] [PubMed]

11. Sluiter, J.K. The new why when designing mandatory medical examinations. Occup. Med. 2017, 67, 325-327. [CrossRef] [PubMed]

12. García-Pérez, L.E.; Alvarez, M.; Dilla, T.; Gil-Guillén, V.; Orozco-Beltrán, D. Adherence to therapies in patients with type 2 diabetes. Diabetes Ther. 2013, 4, 175-194. [CrossRef] [PubMed]

13. Kobuszewska, L.; Sokołowska, B.; Kobus, G.; Urbańczuk, M. Level of knowledge of patients referred for coronary angiography on prevention of secondary coronary heart disease. Probl. Hig. Epidemiol. 2014, 95, 165-169. (In Polish)

14. Viitasalo, K.; Lindström, J.; Hemiö, K.; Puttonen, S.; Koho, A.; Härmä, M.; Peltonen, M. Occupational health care identifies risk for type 2 diabetes and cardiovascular disease. Prim. Care Diabetes 2012, 6, 95-102. [CrossRef] [PubMed]

15. Tankova, T.; Chakarova, N.; Atanassova, I.; Dakovska, L. Evaluation of the Finnish Diabetes Risk Score as a screening tool for impaired fasting glucose, impaired glucose tolerance and undetected diabetes. Diabetes Res. Clin. Pract. 2011, 92, 46-52. [CrossRef] [PubMed]

16. Salinero-Fort, M.A.; Burgos-Lunar, C.; Lahoz, C.; Mostaza, J.M.; Abánades-Herranz, J.C.; Laguna-Cuesta, F.; Estirado-de Cabo, E.; García-Iglesias, F.; González-Alegre, T.; Fernández-Puntero, B.; et al. Performance of the Finnish Diabetes Risk Score and a Simplified Finnish Diabetes Risk Score in a Community-Based, Cross-Sectional Programme for Screening of Undiagnosed Type 2 Diabetes Mellitus and Dysglycaemia in Madrid, Spain: The SPREDIA-2 Study. PLoS ONE 2016, 11, 7, e0158489. [CrossRef] [PubMed]

17. Vandersmissen, G.J.M.; Godderis, L. Evaluation of the Finnish Diabetes Risk Score (FINDRISC) for diabetes screening in occupational health care. Int. J. Occup. Med. Environ. Health 2015, 28, 587-591. [CrossRef] [PubMed] 
18. Bergman, A.; Li, J.; Wang, L.; Schulze, J.; Bornstein, S.R.; Schwarz, P.E. A simplified Finnish diabetes risk score to predict type 2 diabetes risk and disease evolution in a German population. Horm. Metab. Res. 2007, 39, 677-682. [CrossRef] [PubMed]

19. Witte, D.R.; Shipley, M.J.; Marmot, M.G.; Brunner, E.J. Performance of existing risk scores in screening for undiagnosed diabetes: An external validation study. Diabet. Med. 2010, 27, 46-53. [CrossRef] [PubMed]

20. Kennedy-Martin, T.; Boye, K.S.; Peng, X. Cost of medication adherence and persistence in type 2 diabetes mellitus: A literature review. Patient Prefer. Adherence 2017, 11, 1103-1117. [CrossRef] [PubMed]

21. Kramer, M.K.; Molenaar, D.M.; Arena, V.C.; Venditti, E.M.; Meehan, R.J.; Miller, R.G.; Vanderwood, K.K.; Eaglehouse, Y.; Kriska, A.M. Improving employee health: Evaluation of a worksite lifestyle change program to decrease risk factors for diabetes and cardiovascular disease. J. Occup. Environ. Med. 2015, 57, $284-291$. [CrossRef]

22. Elshatarat, R.A.; Burgel, B.J. Cardiovascular risk factors of taxi drivers. J. Urban Health 2016, 93, 589-606. [CrossRef] [PubMed]

(C) 2018 by the authors. Licensee MDPI, Basel, Switzerland. This article is an open access article distributed under the terms and conditions of the Creative Commons Attribution (CC BY) license (http://creativecommons.org/licenses/by/4.0/). 